\title{
Pharyngeal Carcinoma by AJCC v7 Stage
}

National Cancer Institute

\section{Source}

National Cancer Institute. Pharyngeal Carcinoma by A/CC v7 Stage. NCI Thesaurus. Code C91252.

A term that refers to the staging of pharyngeal carcinoma according to the American Joint Committee on Cancer, 7th edition. 